Japan. J. Med. Sci. Biol., 40, 61-74, 1987.

\title{
COMPARISON OF NATURALLY OCCURRING POLIOVIRUS- REACTIVE IMMUNOGLOBULINS IN BOVINE AND EQUINE SERA
}

\author{
Shozo URASAWA, Tomoko URASAWA1, Fumihiko ISHIZAWA \\ and Koki TANIGUCHI \\ Department of Hygiene and Epidemiology, and 1School of Allied Health \\ Professions, Sapporo Medical College, S.1, W.17, Chuo-ku, Sapporo 060, Japan
}

(Received December 17, 1986. Accepted July 13, 1987)

SUMMARY: Bovine and equine sera were screened for poliovirus-reactive immunoglobulins (PRIgs) by means of neutralization and precipitation reactions with type 1 poliovirus. Bovine serum B1826 and B36 were found to contain such PRIgs from their reactivity to various PRIgs-resistant mutants of type 1 poliovirus origin. Neutralization and precipitation reactions with six mono-specific antibodies obtained by absorbing antiserum with each of the six different PRIgsresistant virus mutants revealed that three antibodies were active in precipitation reaction while the others were substantially ineffective. On the basis of the results obtained and the findings reported to date, the mechanism of production of PRIgs in bovine and equine sera was discussed.

\section{INTRODUCTION}

Sera of various animal species have been reported to contain substances active against polioviruses (1). Although many workers were of the opinion that poliovirus-reactive substances are mostly immunoglobulin M (IgM) of the serum (2-5), we demonstrated by radioimmunoelectrophoretic and other methods that they are heterogeneous with respect to the immunoglobulin class: the active substances in equine sera were identified as one of the three immunoglobulins, IgM, slowly migrating IgG and IgG (T) previously referred to as IgA (T) (6), while those in bovine sera were found to be either IgM or IgG globulin $(7,8)$. From these

浦沢正三·石沢文彦·谷口孝喜(札幌医科大学衛生学教室 札幌市中央区南1条西17丁目) 浦沢价子(札幌医科大学衛生短期大学部 札幌市中央区南 1 条西17丁目) 
results, we henceforth use the term poliovirus-reactive immunoglobulins (PRIgs) for these active substances.

Previously, by propagating poliovirus type 1 (Mahoney strain) in cell cultures in the presence of poliovirus-reactive (or PRIg-containing) equine sera, we obtained a number of virus mutants (PRIg-resistant mutants) no more neutralizable with the same PRIgs used for their selection (9). Crossneutralization tests between these resistant mutants and a number of poliovirusreactive equine sera distinguished five groups of sera each containing PRIg with a different specificity, i.e., HN31, HN11, H33, HS77 and H520 (9). Further, antibody-adsorption tests with the five different PRIg-resistant poliovirus mutants revealed that the antiserum against Mahoney strain contained five different monospecific neutralizing antibodies (HN31, HN11, H33, HS77 and H520 antibodies) corresponding in specificity to the five different PRIg mentioned above (9).

In the present article, we report the detection of two new PRIg(s) in bovine serum and the mode of actions of PRIgs with different specificities and compare the activity of various PRIgs in the neutralization and precipitation reactions with that of various monospecific antibodies isolated from rabbit immune serum by the use of PRIg-resistant mutants.

\section{MATERIALS AND METHODS}

Cell cultures and media: A stable line of monkey kidney (MS) cells and HeLa cells used in this study were propagated in Eagle's minimum essential medium (MEM) supplemented with $5 \%$ calf serum and $0.058 \%$ glutamine. Phosphatebuffered saline (PBS, pH 7.3) was used for virus and serum dilution.

Virus: Mahoney strain of type 1 poliovirus and its PRIg-resistant mutants were employed. All viruses were purified by three successive plaque isolation before preparation of stocks. The stock viruses were prepared by infecting MS cells in Eagle's MEM without animal serum. The immunizing antigen of Mahoney strain was grown in HeLa cells with serum-free Eagle's MEM.

Plaque assay: Duplicate MS cell monolayer prepared in 70-mm petri dishes were washed once with PBS, inoculated with $0.4 \mathrm{ml}$ per dish of virus, overlaid after $1 \mathrm{hr}$ incubation at room temperature with $8 \mathrm{ml}$ of Eagle's MEM containing $1.1 \%$ Bacto-agar, glutamine and antibiotics (first overlay medium), and then incubated at $37 \mathrm{C}$ in a humidified atmosphere of $5 \% \mathrm{CO}_{2}$ and air. Two days later, $4 \mathrm{ml}$ of a second overlay medium containing $0.01 \%$ neutral red was added and plaques were counted after an additional incubation for 6 to $8 \mathrm{hr}$. 
Plaque neutralization test: The plaque neutralization test was carried out on MS cell monolayers by inoculating 100 plaque-forming units (PFU)/ $0.2 \mathrm{ml}$ of virus mixed with an equal volume of serial twofold dilutions of serum as described previously (8).

Plaque reduction test: The effect of PRIgs incorporated in the overlay medium on the development of plaques was evaluated in the plaque reduction test. After adsorption of virus (100 PFU) at room temperature for $1 \mathrm{hr}$, MS cell monolayers were overlaid with $8 \mathrm{ml}$ of the first overlay medium containing $10 \%$ of either poliovirus-reactive equine or bovine serum. The plaques were measured and counted usually after 3 day's incubation. Reduction in plaque diameter (PRd) or plaque number (PRn) was calculated by the following equation (8):

$$
\operatorname{PRd}(\mathrm{n})=\frac{\operatorname{NRd}(\mathrm{n})-\operatorname{Rd}(\mathrm{n})}{\operatorname{NRd}(\mathrm{n})} \times 100
$$

where $\operatorname{NRd}(\mathrm{n})$ is the average plaque diameter (or number) in the presence of nonreactive animal serum and $R d(n)$ the average plaque diameter (or number) in the presence of poliovirus-reactive animal serum.

Kinetic neutralization test: The kinetic neutralization test was carried out with approximately $5 \times 105.0 \mathrm{PFU} / \mathrm{ml}$ of virus as described elsewhere (8).

Precipitation-in-agar-gel test: Ouchterlony's double immunodiffusion method was used with $1 \%$ agar (Difco Noble) gel in $0.05 \mathrm{M}$ veronal buffer ( $\mathrm{pH} 8.6$ ). The concentrated and partially purified poliovirus antigen (infectivity of about 1010.5-11.0 PFU/0.1 ml) prepared by differential centrifugation was allowed to react in agar gel against either poliovirus-reactive animal sera or antiserum absorbed with various PRIg-resistant mutants at $28 \mathrm{C}$ for 2-3 days.

Screening of poliovirus-reactive animal sera: Sera collected from healthy cattle and horses were stored at $-20 \mathrm{C}$ without heating. A 1:10 dilution of each of bovine and equine serum samples was examined for the reactivity to poliovirus Mahoney strain in the plaque neutralization test. Serum samples active enough to reduce Mahoney virus plaques to less than $10 \%$ were selected and used. The virusprecipitating activity was examined also in the precipitation-in-agar-gel test with undiluted animal sera.

Preparation of PRIg-resistant Mahoney strain: Since stock Mahoney virus was found to contain a mutant virus resistant to a certain PRIg at a ratio of one to 103-104.5 PFU (depending on the kind of PRIg) of parental virus, the stock virus adjusted to approximately 105.0 PFU was mixed with an equal volume of poliovirus-neutralizing animal serum and the mixture was incubated at $37 \mathrm{C}$ for 1 $\mathrm{hr}$ and at $4 \mathrm{C}$ overnight. It was diluted five-fold with Eagle's MEM and inoculated onto monolayers of MS cells. The cells were incubated at $37 \mathrm{C}$ until CPE appeared. The virus harvest was similarly propagated in MS cells for a total of 6 to 10 passages. A resistant virus was isolated by three-times plaque purification and 
propagated twice in MS cells in the absence of animal serum. Mutants resistant to multiple PRIgs with different specificities were also prepared in a similar manner by growing the virus successively in MS cells in the presence of different PRIgs (10).

A Mahoney virus mutant resistant to virus-precipitating but notneutralizing PRIg was also prepared. Since PRIg having such an activity was contained exclusively in IgG (8), it was isolated from a bovine serum (B36) by DEAE-cellulose chromatography (7). The resistant mutant was selected by the precipitation-in-agar-gel method using the isolated IgG as follows: Two parallel troughs were cut in agar gel. Concentrated Mahoney virus and PRIgG were added to the troughs and they were allowed to react for 3 days at $28 \mathrm{C}$. When a precipitation line was formed, a strip of agar gel was cut out between the precipitation line and the trough containing PRIgG. The agar gel was washed, ground finely and inoculated into a cell culture to propagate selectively such virus that migrated further through the precipitation line without reacting with PRIgG. The propagated virus was concentrated by centrifugation and again allowed to diffuse in agar gel against the same PRIgG. In all, four cycles of precipitation-inagar and subsequent multiplication in cell culture were repeated to select a mutant Mahoney virus no longer precipitable with PRIgG. The mutant virus was finally cloned by two consecutive plaque purification and was named M-B36.

Preparation of anti-Mahoney serum: Mahoney virus grown in HeLa cells was centrifuged at low speed and treated twice with fluorocarbon. Antisera against Mahoney strain were prepared by multiple iv injections of the virus $\left(6 \times 10^{8} \mathrm{PFU}\right)$ into young rabbits confirmed to contain no virus-neutralizing activity in their preimmunization sera.

\section{RESULTS}

\section{Screening of Equine and Bovine Sera by Virus Neutralization and \\ Precipitation Reactions and Mode of Action of Representative \\ Poliovirus-reactive Animal Sera with Different Specificities}

Previous screening of about 1,000 equine sera diluted 1:10 selected 72 sera having strong neutralizing activity against Mahoney strain (9). From the reactivity patterns of these sera in the plaque neutralization test to various PRIgresistant mutants derived from Mahoney strain, five groups of PRIg-containing equine sera represented by HN31, HN11, H33, HS77 and H520 sera were distinguished (9). Later studies suggested that the latter three were partly related one another in the specificity (10). Three were substantially similar in the specificity to HN31 serum, 28 to HN11 serum, 31 to either H33, HS77 or H520 serum, and the remaining 10 were interpreted as mixtures of several different 


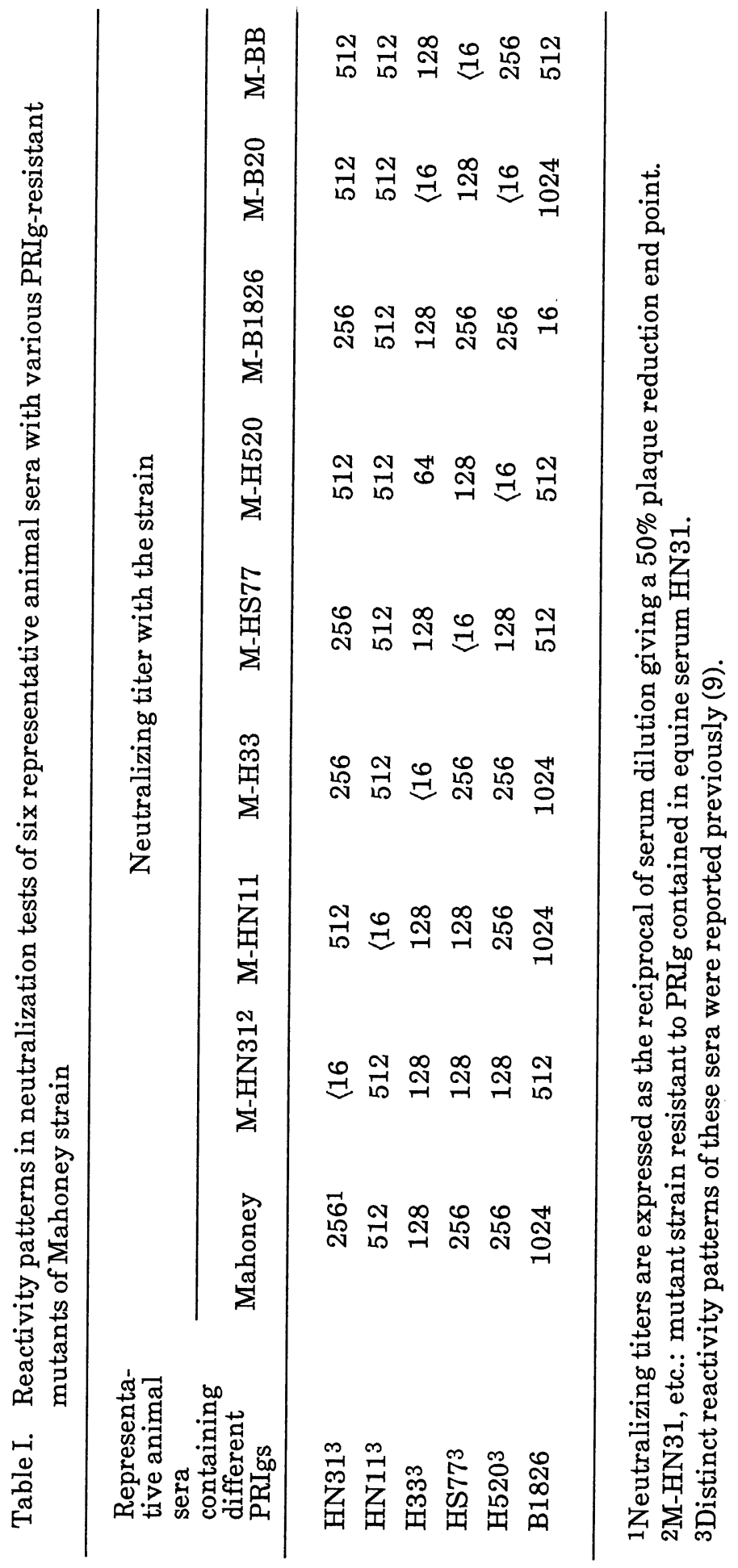




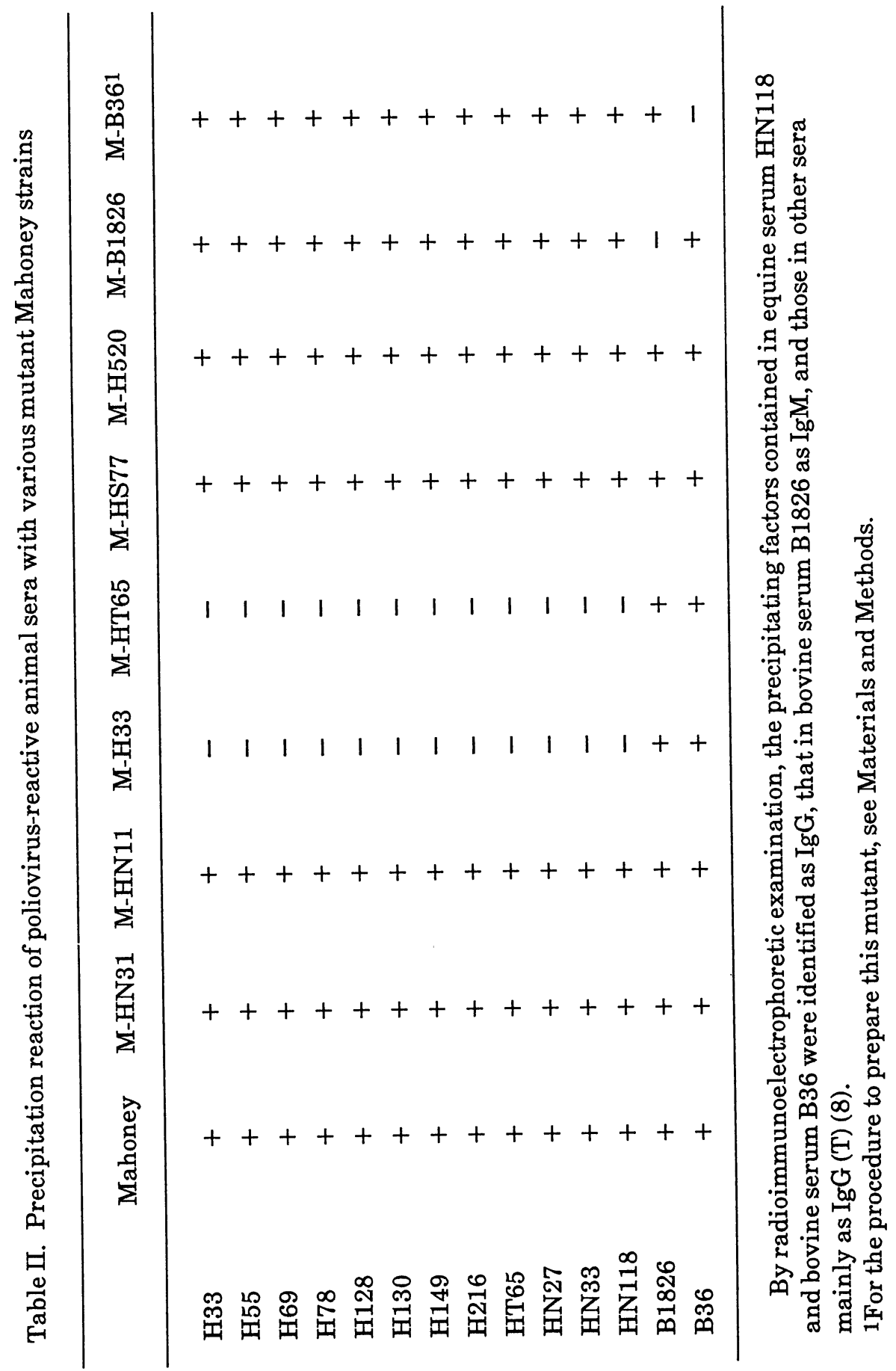




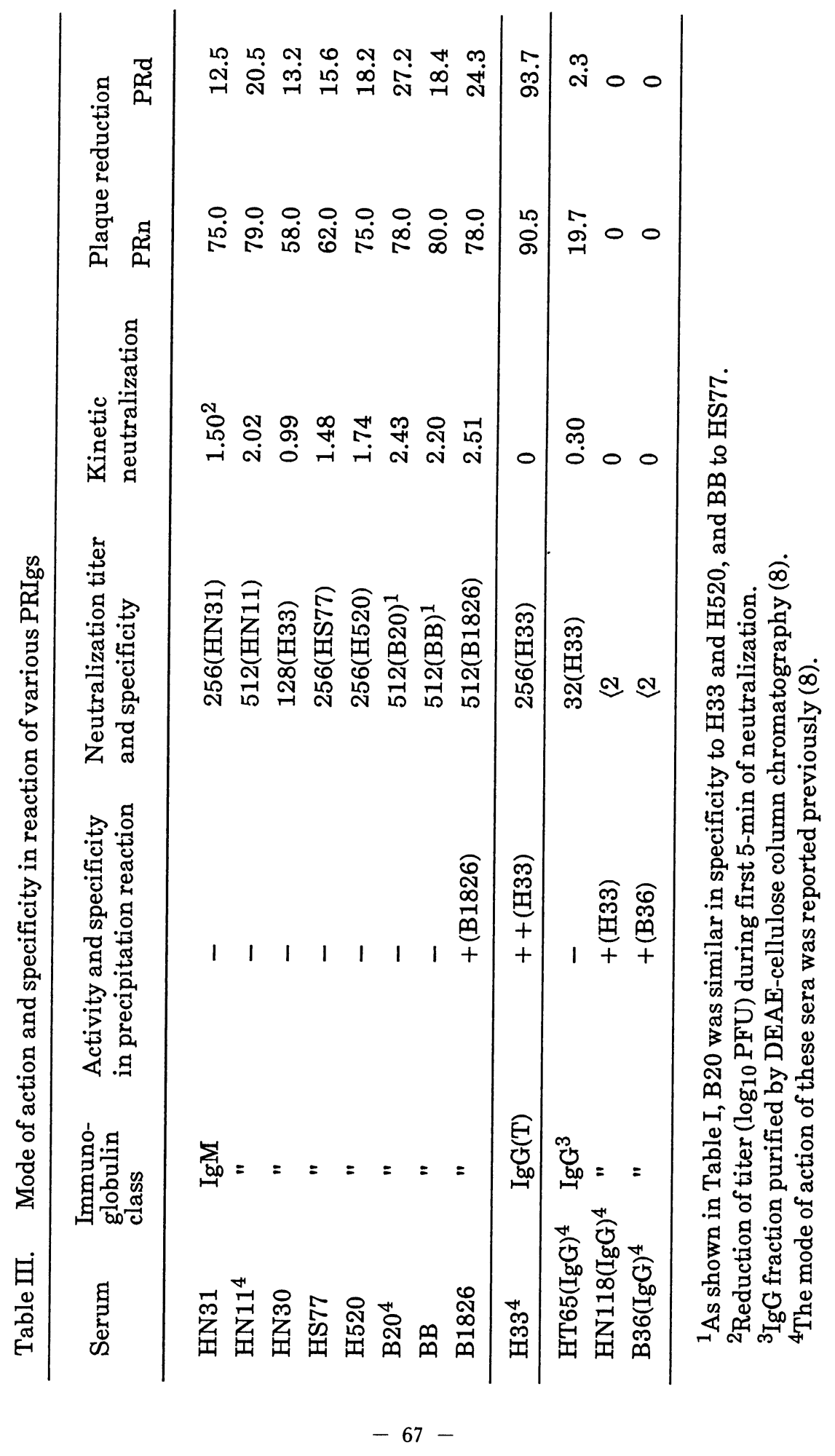


PRIgs (9). Table I summarizes the reactivity patterns in neutralization reaction of representative animal sera against various PRIg-resistant Mahoney mutants.

Similar screening tests on 450 bovine sera have been carried out to date in this laboratory and 84 sera with strong neutralizing activity were selected. Among these, the specificity of selected bovine sera, i.e. BB, B20 and B35, were fully characterized by Hashimoto (11), who indicated the complex composition of PRIgs contained in these three sera. The results also disclosed the close similarity in neutralization specificity of PRIgs contained in bovine serum B20 and equine serum H33, in addition to the partial relatedness in specificity between PRIgs contained in bovine serum BB and B20.

In the present study, the remaining 81 bovine sera with strong activity against Mahoney strain were screened for their activity against the mutant Mahoney virus concurrently resistant to five different equine PRIgs (M-HN31HN11-H33-H520-HS77) and seven sera strongly neutralizing the mutant were obtained. Since these sera were assumed to contain PRIg(s) different in specificity from the previously reported ones, an attempt was made to prepare mutants resistant to each of these bovine sera. It was, however, difficult to prepare mutant viruses against these bovine sera: only one mutant, M-B1826, was obtained after 10 repeated passages in MS cells in the presence of bovine serum B1826. Cross neutralization tests using the mutant, M-B1826, showed that this bovine serum contained a new PRIg different from the known five equine PRIgs (Table I). The close relationship in neutralization specificity between $\mathrm{H} 33$ and B20 and between HS77 and BB is also shown in the table.

Next, equine and bovine sera were screened for their virus precipitating activity against native antigen of Mahoney virus in agar gel. Thirty-four $(4.2 \%)$ of 805 equine sera and 6 (3\%) of 200 bovine sera examined produced positive precipitations. A clear precipitation line was formed only with equine sera; most bovine sera yielded faint and vague precipitation lines. Therefore, selected virusprecipitating equine sera, inclusive of only two precipitating bovine sera B-1826 and B36, were then analyzed by precipitation reaction. Since precipitating PRIgs in equine sera were identified mainly as $\operatorname{IgG}(\mathrm{T})$ globulin (8), these sera were allowed to react in agar gel against various mutant Mahoney strains including MH33 and M-HT65, which were resistant to PRIgs of an IgG(T) globulin nature. As shown in Table II, two major types of PRIgs differing in the pattern of precipitation reaction were distinguished. One was contained in the two bovine sera, B1826 and M-B36, and precipitated all the mutant Mahoney strains but M-B1826 and M-B36. The other contained in equine sera showed the same precipitation pattern against 
various mutant strains irrespective of its immunoglobulin class [i.e. $\operatorname{IgG}(\mathrm{T})$ or IgG]. The fact that the two mutants, M-H33 and M-HT65, lost the ability to precipitate with all equine serum PRIgs in concurrence with their acquisition of resistance in neutralization reaction, and that M-B1826 mutant selected for its lack of reactivity to the neutralizing bovine serum B1826 failed to precipitate with the serum B1826 strongly indicate that both pRIgs operating in virusneutralization and precipitation reactions are identical (12) (Table II). Regarding virus-precipitating PRIg present in bovine serum B36, the previous study (8) disclosed that it belongs to slowly migrating IgG globulin and is deficient in virusneutralizing activity. The uniqueness of this PRIg prompted us to prepare a mutant Mahoney virus (M-B36), which was no more reactive with this PRIg in precipitation reaction. The reaction of M-B36 with various virus-precipitating PRIgs confirmed that the PRIg in B36 is distinct in specificity from other PRIgs contained in equine and bovine sera (Table II).

We have reported that the mode of action of PRIgs in selected animal sera changes depending upon the immunoglobulin class (8). The immunoglobulin class of PRIgs and their mode of action in relation to their reaction specificity are summarized in Table III. PRIgM exhibits strong activities in plaque neutralization, kinetic neutralization and plaque reduction tests. All PRIgs belonging to $\operatorname{IgG}(\mathrm{T})$, represented by $\mathrm{H} 33$ in Table III, show distinct activities in precipitation and plaque reduction (both PRn and PRd) tests. As to PRIgG, one shows the mode of action similar to that of PRIgM mentioned above and the other is active only in the precipitation test. The specificity of reactions represented by H33 was quite unique in that some PRIgs in both equine (H33) and bovine (B20) sera carried this type of specificity, that in equine sera, PRIg with that specificity was present in all of the three classes of immunoglobulin, IgM (e.g. HN30), IgG (T) (e.g. H33) and IgG (e.g. HT65), and that all of the virus-precipitating PRIgs in 12 equine sera examined possessed similar specificities (Table II).

\section{Reactivity and Specificity of Various Monospecific Antibodies in Neutralization and Precipitation Reactions}

Next, cross neutralization reaction was carried out between the six PRIgresistant mutants and the six isolated monospecific antibodies prepared by absorbing anti-Mahoney hyperimmune serum with the corresponding PRIgresistant mutant (Table IV). B1826 antibody obtained by absorption with newly prepared M-B1826 neutralized all PRIg-resistant Mahoney mutants as did the 
Table IV. Distinctness in specificity of B1826 antibody from the previously reported five monospecific antibodies

\begin{tabular}{lcccccc}
\hline \multirow{2}{*}{$\begin{array}{l}\text { Virus } \\
\text { strain } \\
\text { tested }\end{array}$} & HN31ab2 $^{\text {MN11ab2 }}$ & H33ab2 & HS77ab2 $^{2}$ & H520ab2 & B1826ab \\
\cline { 2 - 7 } Mahoney & 1281 & 64 & 128 & 64 & 16 & 128 \\
M-HN31 & $\langle 4$ & 64 & 128 & 64 & 16 & 128 \\
M-HN11 & 64 & $\langle 4$ & 128 & 64 & 16 & 128 \\
M-H33 & 128 & 32 & $\langle 4$ & 16 & 8 & 256 \\
M-HS77 & 128 & 64 & 128 & $\langle 4$ & 16 & 256 \\
M-H520 & 128 & 64 & 128 & 32 & $\langle 4$ & 128 \\
M-B1826 & 128 & 64 & 256 & 64 & 16 & $\langle 4$ \\
\hline
\end{tabular}

${ }^{1}$ Numerals show neutralizing antibody titers. Six monospecific antibodies were prepared by absorption of anti-Mahoney serum with each of the six mutant Mahoney strains, and their neutralizing titers against Mahoney strain were adjusted to 1:64-128 except for the H520 antibody.

2 The specificity in neutralization reaction of these monospecific antibodies was reported previously (9). HN31ab, etc.: HN31 antibody etc.

serum B1826 itself, while the other five antibodies efficiently neutralized M$\mathrm{B} 1826$, indicating that the specificity of B1826 antibody in neutralization reaction is distinct from that of the other five antibodies previously reported (9). The results also disclosed a partial relatedness in specificity between $\mathrm{H} 33$ antibody and HS77 and $\mathrm{H} 520$ antibodies (10).

The reaction between monospecific antibodies and PRIg-resistant mutants were then examined by precipitation reaction. Mixtures of anti-Mahoney serum and various mutant Mahoney strains incubated for $1 \mathrm{hr}$ at $37 \mathrm{C}$ and for 3 days at 4 $\mathrm{C}$ were subjected to this study. For absorbing antiserum, an antiserum-to-virus ratio of $1: 6$ was used on the basis of the results from a preliminary experiment. Absorption experiments with each of the seven mutant viruses including M-B36 revealed that the antisera absorbed with M-HN31, M-HN11 and M-H520 viruses were deficient in virus-precipitating activity against the original as well as mutant 

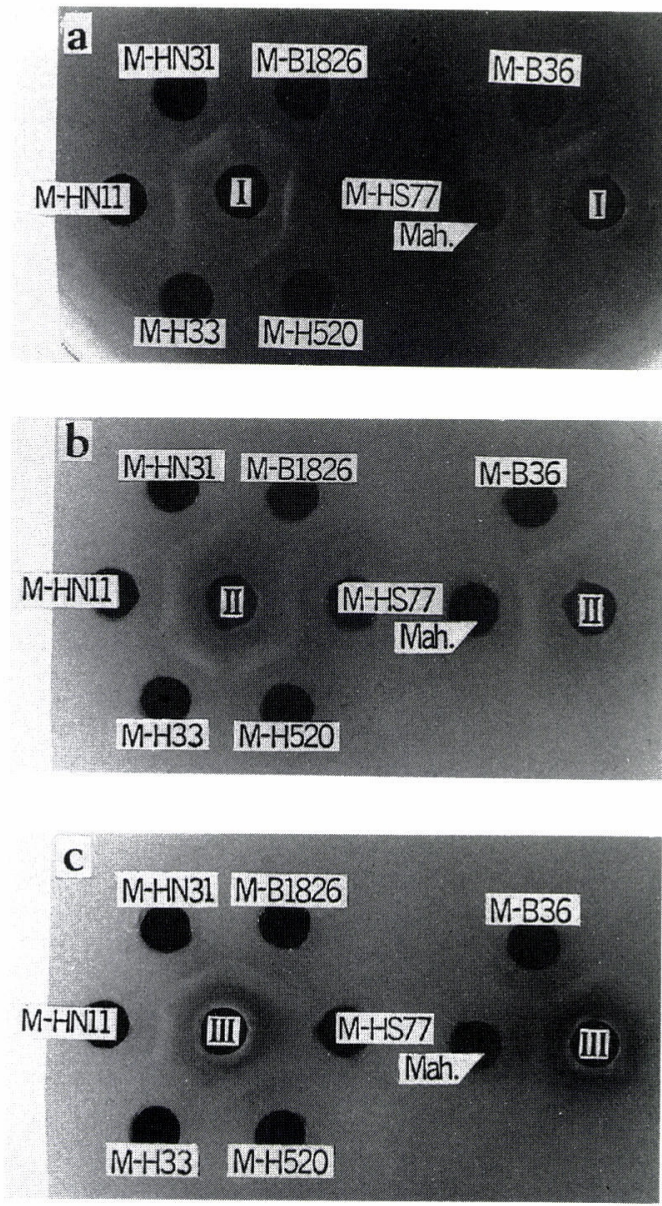

Fig. 1. Precipitation reaction of three monospecific antibodies with original and mutant Mahoney strains.

In the top (a), middle (b) and bottom (c) photographs, the central wells I, II and III received anti-Mahoney sera (R4) absorbed with M-H33, MB1826 and M-HS77, respectively.

Mahoney strains, while H33 and B1826 antibodies corresponding to the virusprecipitating PRIgs, H33 and B1826, precipitated viruses specifically (Fig. 1a and b). Interestingly, HS77 antibody was also found to be able to react specifically with viruses in spite of the lack of virus-precipitating activity of equine serum HS77 (Fig. 1c). Further, the partial one-way relationship between H33 and HS77 
antibodies demonstrated in the neutralization reaction (10) (Table IV) was again suggested in precipitation-in-agar-gel by the faint precipitation line formed between M-H33 and HS77 antibody. M-B36 mutant rendered insensitive to the virus-precipitating PRIg contained in B36 absorbed the precipitating activity from all of the seven anti-Mahoney sera examined (data not shown).

\section{DISCUSSION}

The present study revealed that the specificity of PRIgs have nothing to do with their immunoglobulin class and their mode of action: PRIgs having H33 or related specificity were detected in each immunoglobulin class of slowly migrating IgG, IgG (T) and IgM; further, some of them exhibited pronounced activity in neutralization reaction, while others in precipitation reaction. Although PRIgs of IgM nature were found to exhibit no precipitation reaction (8), PRIgM in bovine serum B1826 was found to do so.

In addition, virus precipitation reaction with monospecific antibodies, H33, HS77 and B1826 isolated by absorbing anti-Mahoney serum with M-H33, M-HS77 and M-B1826, respectively, suggested that while they are directed to the antigenic sites greatly involved in virus-precipitation reaction, monospecific antibodies, HN31 and HN11, are directed to the sites relatively ineffective in precipitation reaction. Although $\mathrm{H} 520$ antibody did not show any virus-precipitating activity, the fact must be taken with some reservation since the titer of H520 antibody contained in these antisera were invariably low. On the other hand, while PRIgG contained in bovine serum B36 was deficient in virus-neutralizing activity, it showed a prominent activity in precipitation reaction. Antiserum absorption with M-B36 nonreactive to that PRIgG in precipitation reaction, however, removed all the precipitating activity, demonstrating that no antibody with such a mode of action (i.e. virus-precipitating but not neutralizing) and specificity is contained in all the antisera examined.

The origin of PRIgs in animal serum is controversial. Cumulative data, however, seem to indicate two possible mechanisms of production of PRIgs: one is that they are produced in animals by infection with poliovirus itself, and the other is that they are produced against some substances sharing a part of the antigen with poliovirus. Isolation of human enteroviruses from and concomitant antibody response in animals $(1,13-15)$ suggest a part of PRIgs having been produced through the former mechanism, while the finding that PRIgs often tend to neutralize selectively a certain strain of poliovirus within the same type (strain- 
specific reactivity of PRIgs) seems to favor the latter mechanism. Further, the facts that while PRIg-resistant mutants are selected without difficulty from the parental virus as described in this paper, it is difficult to obtain a mutant virus resistant to polio-antiserum by growing the virus in the presence of the serum (16) and that a new bovine enterovirus partly cross-reactive to human poliovirus type 2 in neutralization reaction was isolated from stools of Indian cattle (17) also favor the latter possibility. In this respect, the results of the present study showing that the majority of equine and at least a part of bovine PRIgs possessed a definite and a similar specificity (H33 or related specificity) are interesting since this might reflect the exposure of these animals to a similar specific antigen.

Recent studies indicate that the composition of the viral antigen and the mechanism of viral neutralization are better understood by the use of homogeneous antibody populations each capable of reacting with a single epitope, i.e. monoclonal antibodies. In this regard, the close relationship between PRIg and monoclonal antibody was demonstrated in our recent study: reactivity of several monoclonal antibodies prepared against Mahoney strain with various PRIgresistant Mahoney strains disclosed that one of the neutralizing monoclonal antibodies, 4C4, possessed the same specificity as HN31 (18); electronmicroscopic studies revealed that the monoclonal antibody $4 \mathrm{C} 4$ bound only to the vertices of native and heated poliovirus particles (18) as did the HN31 antibody (19); the monoclonal antibody 4C4 failed to precipitate the virus in agar gel (20) as did both the equine serum HN31 and the HN31 antibody. These results also lead us to consider that PRIg is a kind of antibody with a chance reactivity to a definite structure resembling by chance a certain epitope of poliovirus antigen.

\section{REFERENCES}

1. Urasawa, S. (1975): Virus, 25, 213-219 (text in Japanese).

2. Ackermann, W. W. and Dinka, M. (1965): Acta Virol., 9, 526-533.

3. Pagano, J. S., Gilden, R. V. and Sedwick, W. D. (1965): J. Immunol., 95, 909917.

4. Svehag, Sven-Eric (1964): J. Exptl. Med., 119, 517-535.

5. Thomssen, R., Koehne-Barleben, G. and Schober, A. (1966): Arch. ges. Virusforsch., 19, 415-434.

6. Weir, R. C., Porter, R. R. and Givol, D. (1966): Nature, 212, 205-206.

7. Urasawa, S., Urasawa, T., Akahonai, Y. and Kanamitsu, M. (1969): Japan. J. Med. Sci. Biol., 22, 87-99. 
8. Urasawa, S., Urasawa, T. and Kanamitsu, M. (1971); Arch. ges. Virusforsch., $33,113-125$.

9. Urasawa, S., Urasawa, T. and Kanamitsu, M. (1974): J. Immunol., 113, 537542.

10. Urasawa, S., Urasawa, T. and Kanamitsu, M. (1974): Japan. J. Microbiol., 20, 11-16.

11. Hashimoto, N. (1975): J. Immunol., 115, 569-574.

12. Urasawa, S., Urasawa, T., Chiba, S. and Kanamitsu, M. (1968): Japan. J. Med. Sci. Biol., 21, 155-166.

13. Grew, N., Gohd, R. S., Arguedas, J. and Kato, J. I. (1970): Amer. J. Epidemiol., 91, 518-526.

14. O’Connor, J. R. and Morris, J. A. (1955): Amer. J. Hyg., 61, 314-320.

15. Graves, J. H (1973): Nature, 245, 314-315.

16. Ishizawa, F. (1978): Sapporo Med. J., 47, 269-278 (text in Japanese).

17. Nath, N., Balaya, S. and Mohapatra, L. N. (1971): Nature, 229, 342-343.

18. Taniguchi, K., Urasawa, S. and Urasawa, T. (1983): J. Gen. Virol., 64, 28032808.

19. Taniguchi, K., Urasawa, S. and Urasawa, T. (1983): Microbiol. Immunol., 27, 645-648.

20. Taniguchi, K. and Urasawa, S. (1987): Arch. Virol., 92, 27-40. 